\title{
ANÁLISIS DE FACTORES CULTURALES Y PROCESOS DE ESPECIACIÓN EN POBLACIONES DE ECTOPARÁSITOS DE POBLACIONES HUMANAS. El caso particular de los piojos asociados a los humanos
}

\author{
Axel P. RETANA-SALAZAR \\ Universidad de Costa Rica \\ apretana@gmail.com, axel.retana@ucr.ac.cr
}

\begin{abstract}
ANALYSIS OF CULTURAL FACTORS AND PROCESSES OF SPECIATION IN ECTOPARASITES POPULATIONS IN HUMAN POPULATIONS. The particular case of lice associated with humans.
\end{abstract}

Resumen: En este trabajo se exponen la revisión de tema acerca de los factores que pueden afectar la especiación y diferenciación de ectoparásitos en poblaciones humanas. Se presenta una revisión de diferentes grupos de parásitos en humanos y como los factores antropogénicos pueden afectar a estas poblaciones. Se detalla el caso de algunos ectoparásitos que sin específicos presentan diferencias en sus poblaciones aisladas en diferentes hospederos. Se utiliza el caso de los piojos humanos como un caso de estudio debido a que hay controversia acerca de las especies que parasitan al ser humano. Se analiza como los segregados morfológicos hallados en diferentes poblaciones de humanos que se mantienen en relativo aislamiento mantienen trazas morfológicas fácilmente diferenciables incluso a nivel de estructuras asociadas a la genitalia. Las evidencias obtenidas de piojos de momias de la cultura Chinchorro (Chile) indican que esta separación es milenaria. En algunos casos los datos moleculares evidencian la posibilidad de divergencias de linajes que conducen a procesos de especiación simpátrica. Este puede estar sucediendo en las formas de piojos que están parasitando a las poblaciones humanas, pero la evidencia molecular es controversial y los biólogos moleculares se reúsan a utilizar otras evidencias para la determinación de las especies. Este análisis indica que el comportamiento de las poblaciones humanas puede ser una presión de selección más en este proceso, aunque no se refleje con claridad en los procesos genéticos.

Abstract: In this paper we review the topic about the factors that can affect the speciation and differentiation of ectoparasites in human populations. Especially those anthropogenic factors that may affect these biological processes. We present a review of different groups of parasites in humans and how the anthropogenic factors can affect these populations. We detail the case of some ectoparasites that, without being specific, present differences in their isolated populations in different hosts. The case of human lice is used as a case study because there is controversy about the species that parasitize the human being. It is analyzed how the morphological segregates found in different populations of humans that are maintained in relative isolation maintain morphological traces easily differentiable even at the level of structures associated with genitalia. Evidence obtained from mummy lice from the Chinchorro culture (Chile) indicates that this separation is millenarian. In some cases the molecular data show the possibility of divergences of lineages that lead to processes of sympatric speciation. This may be happening in the forms of lice that are parasitizing human populations, but molecular evidence is controversial and molecular biologists refuse to use other evidence for species determination. This analysis indicates that the behavior of human populations may be a further selection pressure in this process, although it is not clearly reflected in genetic processes.

Palabras clave: Ectoparásitos, Factores Antropogénicos, Aislamiento Cultural, Separación De Especies, Selección Natural.

Ectoparasites, Anthropogenic Factors, Cultural Isolation, Species Separation, Natural Selection. 


\section{Introducción}

La teoría de la Evolución de Darwin-Wallace intenta explicar el proceso de selección natural y como este opera en la selección de caracteres que se ajustan de mejor manera a las necesidades medioambientales de los organismos. Uno de los factores que pueden alterar este equilibrio produciendo evolución direccional de las especies son las relaciones entre organismos. Además, los cambios en el ambiente como es el cambio climático pueden dirigir la selección de caracteres en las poblaciones (Retana-Salazar \& Retana-Salazar 2015). También es un hecho que las relaciones bióticas como el parasitismo o la depredación pueden ser importantes fuentes de presión selectiva sobre las poblaciones. Esto se puede ser ilustrado en los cambios morfológicos sufridos por las poblaciones de bacterias cuando son depredadas por protozoarios (Justice et al. 2008). Este es solo un ejemplo de cómo pueden reaccionar las poblaciones ante las presiones de selección. De igual manera el calentamiento global ha conducido a que las especies de zonas templadas colonicen las regiones tropicales con lo que generan una presión sobre las especies del trópico que puede resultar en competencia y extinciones. El clima en este caso forza una situación de cambio (Retana-Salazar \& Retana-Salazar 2015). Muchos factores ambientales son presiones como la disponibilidad alimentaria que pueden llevar a cambios en la morfología de los organismos como sucede con algunos reptiles que pierden tamaño debido a una dieta deficiente (Wikelski \& Thom 2000).

Las actividades antropogénicas han empezado a ser estudiadas como factores que pueden ejercer presión sobre las poblaciones naturales de otras especies, afectando sus procesos ecológicos, fisiológicos y sus respuestas al medio lo que genera cambios a nivel de los caracteres de las poblaciones o sus distribuciones generando procesos de segregación o extinción de poblaciones. Este efecto humano no es novedoso, pero actualmente con la facilidad de desplazamiento, el desarrollo de cambios culturales en los comportamientos humanos y los efectos de la tecnología en el desarrollo humano se han incrementado estos factores de presión selectiva sobre las poblaciones de otros organismos.

Habitualmente se analiza el efecto antropogénico sobre animales que han sido cazados por el hombre o que están sometidos a factores de presión como son los insectos plaga (Retana-Salazar \& Retana-Salazar 2015), pero son muy pocos los estudios de los efectos que generan los factores antropogénicos sobre las poblaciones de especies que nos parasitan.

En este trabajo se analizan algunos casos en los que las alteraciones culturales de algunos comportamientos humanos pueden ser estudiados como presiones selectivas sobre la respuesta a largo plazo de los organismos asociados a las poblaciones humanas. Para esto inicialmente se presenta una revisión de como el humano puede tener efecto sobre las poblaciones de otras especies, para profundizar en el tema de los factores socio-culturales que pueden afectar a las poblaciones de algunas especies asociadas de alguna forma a las poblaciones humanas.

\section{Materiales y Métodos}

Para el desarrollo de este trabajo se han utilizado datos tomados de una amplia revisión bibliográfica utilizando las bases de datos de texto completo referentes al área de Salud (http://sibdi.ucr.ac.cr/dbsalud.jsp), Interdisciplinarias (http://sibdi.ucr.ac.cr/dbinterdisci. jsp) y Ciencias Básicas (http://sibdi.ucr.ac.cr/dbciencibasi.jsp) suscritas al Sistema de Bibliotecas, Documentación e Información (SIBDI) de la Vicerrectoría de Investigación de la Universidad de Costa Rica. De igual forma se han revisado fuentes en línea que son de interés y son serias en sus publicaciones. Se revisó para la ejecución de este trabajo un total de 85 trabajos y se citan un total de 56 en la revisión formal llevada a cabo y presentada en este estudio. 


\section{Desarrollo}

En esta sección se sintetizan los datos obtenidos de la búsqueda de información efectuada en las fuentes bibliográficas y en línea y se exponen las ideas que pueden surgir de este análisis de datos.

Este apartado se divide en cuatro grandes secciones: A) Conjeturas generales de como los factores antropogénicos afectan procesos de selección en poblaciones de otros organismos promoviendo tanto procesos de especiación como de extinción, una segunda sección B) sobre las especies de ectoparásitos asociados a las poblaciones humanas, incluyendo algunos hematófagos de vida libre como son algunas moscas o los mosquitos transmisores de enfermedades como el dengue, el zika o la malaria entre otras, se incluyen también los chinches que pueden transmitir el mal de chagas, C) una sección de análisis de datos de como los factores culturales han afectado las poblaciones de artrópodos ectoparásitos de poblaciones humanas y como estos factores antropogénicos han afectado las poblaciones de piojos asociados a las poblaciones humanas y D) una sección dedicada al análisis de los procesos biológicos de especiación y los factores culturales que pueden afectar los mismos.

\section{A) Factores antropogénicos y su efecto sobre poblaciones naturales}

Es evidente que la humanidad ha tenido un efecto sobre las poblaciones naturales de otras especies, como sucede en cualquier caso en la naturaleza. No obstante, hay pocos datos registrales del impacto humano sobre los ecosistemas naturales.

Las actividades como la caza han promovido procesos de extinción, mientras que otras actividades como la domesticación o alteración de algunos medios ambientes pueden afectar los procesos de selección estabilizadora entre poblaciones que no se hallan bien aisladas desde el punto de vista genético, evitando el proceso de separación, mientras que en otros casos la actividad humana amplia los ámbitos de distribución de las poblaciones causando aislamiento y en consecuencia promoviendo procesos de especiación.

El proceso de especiación es poco conocido, pero la ruta para el mismo empieza muchas veces con la disrupción de poblaciones, las cuales ante diferentes presiones de selección empiezan a fijar caracteres diferenciales. Uno de los procesos más comunes asociados desde Darwin y Wallace con la segregación de especies es la alopatría, o la separación física de poblaciones que al no tener contacto empiezan un aislamiento genético que las puede llevar a crear especies nuevas (Wiley 1981). Este es el mecanismo más sencillo de estudiar y nos ha parecido siempre a los biólogos el más evidente y quizás más sencillo de entender.

Los factores asociados a las poblaciones humanas pueden afectar la evolución de las poblaciones naturales de otros organismos (Taylor et al. 2006). Otros estudios se han enfocado los efectos directos de los humanos sobre los procesos como la radiación de los grupos (Hendry et al. 2006).

Las tasas de extinción de especies se incrementan en muchos casos con la actividad humana. Por ejemplo, es sabido que la llegada de los humanos al medio del pájaro dodo (Raphus cucullatus) terminó siendo unos de los principales detonantes de su extinción. No solo por el efecto de la caza de esta especie que era fácilmente atrapada por los cazadores, sino por la fauna que acompañó los asentamientos humanos como por ejemplo cerdos ( $\mathrm{Sus}$ scrofa), perros (Canis lupus familiaris), gatos (Felis silvestris catus), ratas (Rattus norvegicus) entre otras que además depredaban los nidos de esta especie de ave. Con la introducción de nuevas especies foráneas se incrementó la susceptibilidad a enfermedades que eran desconocidas, además del efecto sobre los bosques de los que dependían estas poblaciones. Se considera que pudo existir hasta el año de 1690 (Macmillan 2000).

Más atrás en la historia de la humanidad encontramos que el Milodón (Mylodon darwini) desapareció hace cerca de 10000 años entre las causas que se suponen pudieron contribuir a la extinción de esta especie de mamífero gigante fueron: 1) un efecto de un cambio cli- 
mático que afectó la disponibilidad alimentaria de esta especie, 2) actividad volcánica de la época ayudó a la extinción, 3) caza indiscriminada de las primeras poblaciones humanas que llegaron a América del Sur y 4) una conjunción de todos los factores anteriores.

En el lago Ohrid entre Macedonia y Albania se indica que en la actualidad el impacto antropogénico puede poner en peligro una serie de especies endémicas restringidas a áreas pequeñas para su subsistencia, de esta forma esta fauna se halla en una condición vulnerable gracias a los efectos antropogénicos (Wilke et al. 2009).

Hendry (2009) presenta una breve discusión acerca de la intervención humana en los procesos de especiación o de restricción de la especiación. En el caso en que los humanos promueven especiación, encontramos que los humanos pueden afectar el ámbito de distribución de las poblaciones, rompiendo la continuidad de las poblaciones. Esta disrupción puede promover caminos evolutivos independientes. Además, los humanos pueden proveer nuevos hábitats que pueden dar cabida a especiación ecológica. Un ejemplo de esto es la introducción de plantas en localidades de las que no son nativas, lo cual puede estar seguido por la evolución de nuevas razas de insectos especializados en estas plantas, las cuales pueden llegar a manifestar aislamiento reproductivo en pocas décadas.

Lonicera spp es una especie de planta nativa de Asia que ha sido introducida en América del Norte (EE.UU.). Esta planta es parasitada por una especie de mosca del género Rhagoletis donde se registra el principio de un proceso de especiación ilustrando además como la hibridación puede ser un mecanismo efectivo para la especiación (Hendry 2009).

Las mismas actividades humanas que promueven especiación pueden promover extinción de especies. Como se expuso antes en el ejemplo de la planta Lonicera spp y sus moscas asociadas, las introducciones efectuadas en EE.UU. conducen a patrones de separación de las especies. Hay casos documentados donde la invasión de especies promovida por el hombre se convierte en una presión de selección negativa sobre las especies nativas creando un efecto de extinción de las mismas (Deutsh et al. 2008).

Buswell y colaboradores (2011) efectúan un estudio de 23 especies de plantas introducidas en New South Wales, Australia y 1900 especímenes en donde determinan que en un plazo de 10 años se registran cambios morfológicos consistentes en la mayor parte de estas especies. Esto indica cambios en las poblaciones y es evidente que pueden ser debidos a la plasticidad fenotípica como a los factores de aislamiento.

De igual forma la alteración climática mediada en gran medida por la actividad antropogénica conduce a que haya variación en las poblaciones, por ejemplo, hay incremento de la biodiversidad en las cumbres montañosas debido a estas alteraciones climáticas, de esta forma en las simas alpinas hay mayor diversidad florística a partir de 1985 cuando se empiezan a registrar los cambios en el calentamiento global (Walther et al. 2005).

Un fenómeno similar se registra con las poblaciones de insectos que logran colonizar el trópico gracias a los efectos del cambio climático dejando a las especies nativas en directa desventaja contra las nuevas poblaciones invasoras (Deutsh et al. 2008, Retana-Salazar \& Retana-Salazar 2015).

De igual manera, las tasas de cambio genético son mayores en aquellas especies que han sufrido caza por los humanos que en aquellas que no (Stenseth \& Dunlop 2009). Es importante señalar que las introducciones enfermedades y parásitos en sitios protegidos como las Islas Galápagos han sido informados como problemas de presiones de selección no naturales que pueden estar cambiando el rumbo de la selección natural por factores antropogénicos (Deem et al. 2010). En este caso la introducción de una especie de mosca cuyas larvas son parásitas de los pinzones han causado problemas a estas poblaciones por lo que se han tomado medidas inmediatas como el control con aplicaciones de insecticidas, sin embargo, esto constituye una importante presión de selección sobre las poblaciones de la mosca parásita con lo que se están seleccionando sus poblaciones en una dirección diferente a las condiciones naturales. Este fenómeno se ha documentado en las especies de 
parásitos asociados a los humanos como es el piojo de la cabeza, en donde se ha registrado que al menos en 25 estados de los EE.UU. la aplicación de las medidas de control de estas poblaciones las ha hecho resistentes a estos productos (Oaklander 2015). Lo mismo puede suceder con esta mosca causando que el problema en un tiempo determinado se agrave.

Por otra parte, el proceso inverso también puede darse. Los humanos pueden promover la unión de grupos que presentan distribuciones divergentes y que no han acumulado suficientes diferencias como para prevenir esta fusión (Hendry 2009).

De igual forma la actividad humana puede obstruir la especiación ecológica reduciendo la diferenciación de recursos que se hallaban separados (tipos de comida), como introduciendo un recurso intermediario que se traslapa en sus poblaciones. Las acciones antropogénicas pueden alterar las señales de apareamiento que mantienen a las especies separadas. Por ejemplo, al incrementar la turbidez del agua, se alteran los procesos de selección de la pareja por color (Hendry 2009).

Las alteraciones humanas muestran claramente su relación con los cambios en el sentido de la selección, produciendo selección disruptiva que puede dar como resultado nuevas especies, como procesos en los cuales se promueva una selección estabilizadora que hace que poblaciones diferentes entren en contacto y produzcan fenotipos intermedios por falta de barreras y estas alteraciones pueden afectar los patrones de comportamiento de las especies, cambiando la dirección de la evolución.

De esta forma, es factible que estos procesos de intervención humana influyan en procesos de conservación y de preservación de las especies. No obstante, hay otra dimensión en la cual los factores culturales pueden afectar directamente aquellas especies que parasitan al ser humano, donde los usos culturales, creencias y comportamientos pueden actuar como factores se selección positiva o negativa sobre las poblaciones de estas especies parásitas. Hay varios casos de este tipo que serán analizados, pero en especial el de los parásitos como los piojos de los humanos y las presiones de selección sobre ellos.

\section{B) Ectoparásitos de humanos}

En el caso de las especies parásitas uno de los factores determinantes de este mecanismo es la concepción de que el hospedero es el medio ambiente de los parásitos (Huyse et al. 2003). De esta forma para una pulga como Tunga penetrans es indispensable mantenerse en el hospedero, donde produce una reacción tisular que la protege.

La lista de especies de artrópodos que afectan directamente al hombre como parásitos o que ocupan de sus poblaciones como un factor de desarrollo biológico no son muy numerosas si se toman en cuenta como grupos de especies, en casos particulares pueden ser muchos y con muy diversas estrategias adaptativas. En esta sección se presenta un resumen de las características principales de estas especies para entrar luego en el análisis de como los factores culturales pueden ayudar a su control o más bien promover las poblaciones de estas especies.

B.1) Miasis. Las miasis (denominadas como gusaneras) son infecciones llevadas a cabo en la piel de mamíferos por larvas de moscas. Aprovechan heridas para poner sus huevecillos o los dejan en la piel de tal manera que las larvas logran penetras la piel, donde estas empiezan a desarrollarse dentro del tejido. Es común este comportamiento en familias como Calliphoridae, Oestridae donde se registra una especie asociada a los humanos específicamente Dermatobia hominis, los huevos pueden ser puestos directamente por las moscas en la piel o pueden utilizar vectores, es decir ponen los huevos en otras especies de moscas que al visitar los hospederos dejan los huevo en la piel. Otra especie que presenta este comportamiento es Cochliomyia hominivorax, la cual ataca a varias especies de mamíferos en donde 
se alimenta de tejidos sanos, incluyendo tejidos humanos. Las moscas que hacen miasis no suelen ser específicas de un hospedero, pero varias pueden atacar al humano.

B.2) Mosquitos. En esta categoría entran una serie de especies que en diferentes regiones del mundo pueden tener efectos directos sobre las poblaciones humanas, tanto por su efecto directo como por su función como vectores de otras enfermedades como virus (Dengue, Zika, Chicungunya) o protozarios como la malaria que es un problema serio en África. Entre las especies que más afectan al ser humano se encuentran una serie de especies que se hallan en diferentes regiones del mundo como Aedes aegypti, Anopheles maculipennis, Culex pipiens entre otras. La biología de estas especies es muy particular y los factores culturales pueden ser determinantes en su distribución. Algunas especies como las del género Lutzomiya spp se asocian a sistemas forestales no alterados como son los bosques primarios, por lo que la transmisión de enfermedades como el papalomoyo producida por una Leishmania sp se ve restringida a zonas rurales de invasión del bosque primario, que pone estas especies en contacto con las poblaciones humanas. Son muchas las especies de mosquitos y dípteros que presentan efectos sobre las poblaciones humanas de forma directa o indirecta. Dentro del Orden Diptera son numerosas las especies que de alguna forma interactúan con nosotros causando problemas a los sistemas de salud y de producción.

B.3) Chinches de las camas. En esta categoría hay al menos dos especies que pueden causar problemas al hombre. La de más amplia distribución que se encuentra en todo el mundo y puede llegar a ser plaga en los hoteles de Europa y EE.UU. es Cimex lectularius, que pertenece a la familia Cimicidae y se alimenta exclusivamente de sangre. Aunque puede alimentarse de la sangre de múltiples mamíferos se sabe que prefiere la sangre de los humanos, por lo que se asocia a sus ecosistemas urbanos. Esta especie es más activa de noche, pero no es exclusivamente nocturna, cuando pica habitualmente no es percibido por el hospedero. Aunque no se le conoce como vector de enfermedades sus ataques pueden causar perjuicios a la salud tales como urticaria por los múltiples piquetes, manifestaciones alérgicas y hasta efectos psicológicos debidos al deterioro de la piel. Esta especie puede infestar las camas de los hoteles creando serios problemas por las picaduras de estos insectos a los huéspedes.

Otras especies asociadas a las camas y las paredes cercanas a las camas son los chinches bebe sangre entre los que encontramos las especies de una subfamilia de Reduviidae, los Triatominae donde se registran cerca de 130 especies todas hematófagas. La mayor parte de estas especies son americanas y unas pocas se informan en Asia, África y Australia.

Muchas de las especies de triatominos son vectores potenciales de la enfermedad de Chagas que es producida por un protozoario de la especie Trypanosoma cruzi, sin embargo, las especies que como Triatoma arthurneivai, T. bassolsae, T. barberi, T. brasiliensis, T. carrioni, T. circummaculata, T. costalimai, T. delpontei, T. dimidiata, T. dispar, T. eratyrusiformis, T. infestans, T. juazeirensis. T. lecticularia, T. lenti, T. longipennis, T. maculata, T. matogrossensis, T. mazzottii, T. melanica, T. melanocephala, T. melanosoma, T. neotomae, Triatoma nigromaculata, T. nítida, Triatoma pallidipennis, T. patagónica, T. peninsularis, T. petrochiae, T. phyllosoma, T. picturata, T. platensis, T. protracta, T. pseudomaculata, T. recurva, T. rubida, T. rubrofasciata, T. rubrovaria, $T$. sanguisuga, T. sinaloensis, $T$. sórdida, T. tibiamaculata, T. venosa, T. vitticeps y algunas especies del género Rhodnius como es el caso de Rhodnius prolixus que se han adaptado a vivir con los seres humanos son consideradas vectores importantes del parásito responsable de esta enfermedad.

Las especies enlistadas arriba son en realidad las que se asocian a la posible transmisión de $T$. cruzi a los humanos. Estos chinches necesitan sangre para su ciclo vital por lo que se alojan en las rendijas de las paredes y de las camas como en lugares peridomiciliares don- 
de se almacena leña y otros productos, lo que los mantiene cerca de la población humana, adaptándose a las condiciones ambientales promovidas por la actividad humana.

B.4) Trombiculidae. Son una serie de ácaros que pueden atacar la piel de los humanos causando dermatitis e infecciones por el prurito exagerado que producen, generando problemas de salud. Son de vida libre y pasan parte de su vida larvaria como parásitos por lo que al nacer suben a la hierba donde se suben en los posibles hospederos que transiten por esa zona para alimentarse unos días antes de desprenderse y seguir el ciclo de vida libre.

B.5) Ixodoidea. Conocidas como garrapatas, hay tres familias que son garrapatas que son Ixodidae, Argasidae y Nuttalliellidae. La última representada solo por una especie africana. Las garrapatas presentan una relación difusa con sus hospederos.

Algunas especies como los Argasidae son básicamente asociadas a murciélagos y aves esto las lleva a que cuando atacan la humano pueden causar serios cuadros de anafilaxis. Los humanos al colonizar nuevos ambientes rurales alteran el equilibrio y disponibilidad de sitios para que los murciélagos perchen o las aves hagan sus nidos. Esto obliga a estas especies a colonizar los cielos de las viviendas humanas en el caso de los murciélagos o deben hacer sus nidos en árboles de parques residenciales o de zonas de jardín, con lo que se incrementa la posibilidad de exposición a estas especies de parásitos.

Los Ixodidae son los más comunes, habitualmente atacan mamíferos, aunque algunas atacan a especies de reptiles y de anfibios. Comúnmente se les encuentran atacando perros, caballos, cerdos, ganado vacuno entre otros lo que los pone en contacto directo con las poblaciones humanas. Las garrapatas pueden afectar a los humanos produciendo dermatitis y transmitiendo enfermedades que no solo afectan directamente a los humanos sino a sus animales de producción como es el caso del ganado vacuno.

B.6) Demodex spp. Estos son ácaros de muy reducido tamaño y habitan los folículos de la piel de los humanos en especial, hay especies asociadas a la piel de animales domésticos como son los perros. Los hay en perros también y en otras especies. Habitualmente no generan problemas excepto en algunos casos donde se asocian a la rosácea de la piel por poblaciones superiores a lo normal. Pueden en algunos casos asociarse a procesos de enfermedad de la piel como es el acné o algunas dermatitis. Se transmiten a los hijos a través del contacto con los padres y otras personas, cuando el niño nace no presenta infestación. Esta infestación es común en las poblaciones humanas asociada a la piel donde se alimentan de células muertas, aunque no hay evidencia de que no ataquen las células sanas y vivas.

B.7) Sarcoptes scabeie. Es el primer caso de un agente etiológico asociado a una patología como es la sarna. Desde el siglo XVII se conoce el efecto de este ácaro. La especie fue estudiada y asociada con la sarna por el investigador italiano Diacinto Cestoni en el siglo XVIII indicando que la sarna es producida por Sarcoptes scabiei var hominis.

Hay varios aspectos de la biología de este parásito de interés para las poblaciones humanas. Causan un prurito serio y las lesiones por el rascado pueden causar asociación con otros problemas de la piel como es eczema, dermatitis y es transmisible a otros seres humanos por contacto directo, por lo que generalmente aparece en zonas expuestas y de alto contacto como las manos y los brazos.

Las lesiones pueden tener también efectos psicológicos y reacciones sociales, puesto que se asocia con problemas de higiene y de salud. S. scabiei var canis se asocia a la piel de los perros y eventualmente puede causar zonas de prurito en humanos, pero no prolifera, debido a que la infestación se autolimita. 
Estudios llevados a cabo comparando diferentes variedades del ácaro han mostrado diferencias morfológicas y de comportamiento en las variedades canis, suis y hominis (Calderón \& Sánchez 1996). Estos datos indican que se trata posiblemente de especies diferentes.

B.8) Tunga penetrans. Esta pulga es originaria de América Central y Sur América, el ciclo de vida es típico de una pulga en donde las formas larvales se desarrollan en el ambiente en vida libre, al llegar el momento de la pupación hacen un capullo de seda que las protege y que es estabilizado si caen en un medio rico en arena o polvo que ayuda a estabilizar al capullo. Factores ambientales como la falta de arena o polvo o fuertes lluvias alteran las poblaciones.

El macho se mantiene móvil después de alimentarse de sangre, mientras que las hembras clavan la cabeza en el tejido del hospedero donde se forma una madriguera en la piel donde se aloja dejando un orificio abierto en la parte distal del abdomen a través de este agujero la pulga puede respirar, defecar, copular y expulsar huevos al medio mientras se alimentan de los vasos sanguíneos del hospedero. Vive en las capas dérmicas tanto cutáneas como subcutáneas. Es conocida en algunos sitios como nigua. En algunos lugares de América Latina se hacen imágenes de una niña desnuda tratando de quitarse estas pulgas de los dedos de los pies, esta figura llamada en algunos lugares como la niguenta, se ha utilizado como adorno de las casas y se le ha dado la connotación de traer la suerte a los hogares que tienen esta imagen. Este es un caso donde el parásito adquiere un valor social agregado que puede afectar de forma positiva sus poblaciones.

B.9) Pulex irritans y Ctenocephalides spp. La primera es conocida como la pulga de los humanos esta especie presenta una serie de hospederos. Entre ellos varias especies de roedores. Por el origen del género Pulex donde las especies están limitadas al Neartico y el Neotropico la única especie de amplia distribución es Pulex irritans que se asume se originó en América del Sur.

Otras pulgas que atacan al hombre como Ctenocephalides felis puede causar problemas a la salud humana de forma directa por sus picaduras en la piel que pueden generar procesos dermatológicos infecciosos o indirecta cuando actúa como vector de patógenos que pueden comprometer la salud humana.

La especie $P$. irritans presenta un amplio rango de hospederos desde humanos, perros, gatos, ratas, cobayos y pecaríes y colonizaron Eurasia en una época posglacial. Este insecto causa problemas de la piel como por ejemplo la pulicosis que es efecto de dermatitis causado por los piquetes y que puede agravarse con el rascado, algunas veces el prurito dificulta el sueño o produce algunas afecciones psicológicas en el paciente. Esta condición puede ser causada por diferentes especies de pulgas como Pulex irritans, Ctenocephalides felis y Ctenocephalides canis como las más comunes en las poblaciones humanas.

B.10) Pediculus humanus humanus y Pediculus humanus capitis. Los piojos asociados a los humanos presentan particularidades que los han mantenido en discusión desde hace más de dos siglos. La cantidad de variedades descritas y sinonimizadas es amplia y los criterios que se han utilizado han sido básicamente morfológicos.

En los últimos años se han estudiado las poblaciones de manera molecular pero las muestras de diferentes regiones son muy heterogéneas y en algunos casos son además muy reducidas. Los biólogos moleculares fundamentados en datos de secuencias consideran que todas son de una única especie y dos morfotipos que indican que hay diferencias entre ellas.

Sin embrago, los taxónomos no presentan un acuerdo para separarlas por lo que las consideran como una única especie de manera convencional, aunque su biología sea diferente, lo cual es un efecto de la necesidad de una clasificación cómoda en vez de una clasificación que refleje los procesos biológicos que es la clasificación natural. Igual sucede con las for- 
mas aisladas de otros primates donde las únicas que se aceptan como diferentes especies son las asociadas a los primates del Nuevo Mundo y las del chimpancé, las asociadas a otros grupos se mantienen en duda por los taxónomos clásicos y de estos grupos no hay datos moleculares disponibles excepto en el caso del chimpancé.

B.11) Pthirus pubis. Este es el piojo del pubis de los humanos o ladilla. En esta familia se encuentran solo dos especies Pthirus pubis que es el parásito de los humanos y Pthirus gorillae que es la especie parásita del gorila (Gorilla gorilla).

Estas especies presentan modificaciones del patrón estructural que responden a las condiciones ambientales. De esta forma la distancia entre los pelos que son su sustrato de sujeción al hospedero, se hallan más separados que lo normal en otras especies lo que ha provocado cambios morfológicos a nivel del tórax y la separación de las coxas, provocando el desplazamiento de los espiráculos al dorso de los primeros segmentos abdominales, además las placas paratergales están modificadas en forma de tubérculos con setas distales que son de ayuda en la sujeción y desplazamiento entre el pelo del hospedero.

En el caso particular de $P$. pubis, la especie que parasita al humano, encontramos que se halla limitada a las regiones del cuerpo donde crece vello androgénico, lo que le da una distribución diferencial entre hombres y mujeres, pudiendo existir poblaciones más grandes en los varones que en las mujeres por la cobertura corporal de vello.

\section{C) Factores antropogénicos que afectan a las poblaciones de ectoparásitos}

Los parásitos revisten un problema particular en la biología humana. Estos organismos se encuentran bajo una presión de selección artificial muy alta debido al combate que tenemos contra ellos. Sin embargo, algunos factores del comportamiento humano pueden favorecerlos o actuar en contra de sus poblaciones. En este apartado se analizan los factores culturales de los humanos que afectan las actividades parasitarias y que eventualmente podrían conducir a procesos de especiación en algunos casos.

C.1) Dípteros. En este apartado se incluyen las miasis como los adultos de este grupo debido a que la mayor parte de las larvas que pueden causar algún problema a los humanos son de moscas. El control de las especies de Diptera ha sido particular por especies en muchos casos. En algunas ocasiones se ha utilizado liberaciones de machos estériles para reducir las poblaciones o aplicaciones de insecticidas que bajan las poblaciones y alejan a los individuos que quedan vivos en diversas especies de dípteros que afectan al hombre en su salud (Takken \& Weiss 1999) o su producción alimentaria.

En la mayor parte de los casos los controles son químicos. Hay controles culturales como el uso de repelentes en la piel, el uso de ropa suelta y que cubre totalmente la mayor parte de piel expuesta (Ministerio de Salud Pública, Uruguay 2011). Algunas prácticas culturales son de interés para alejar a los mosquitos y moscas como quemar las bostas (boñigas) del ganado y de los caballos al final de la tarde en una fogata donde el humo ahuyenta a los mosquitos y moscas.

En otros casos se elabora un cebo casero en base a agua con azúcar y levadura que genera $\mathrm{CO}_{2}$ que atrae a los mosquitos y hematófagos a trampas de donde no pueden salir. Por otra parte, los fumadores utilizan el humo del cigarrillo como repelente por el efecto insecticida de la nicotina y el humo del alquitrán, en algunos casos los fumadores que utilizan mucho el fumado diariamente exudan microdosis de nicotina que funciona como repelente en la piel. Las campañas de fumigación para evitar criaderos de mosquitos como la educación acerca del control de estas poblaciones han sido importantes para que se adopten comportamientos por parte de la población donde se evitan los criaderos de mosquitos vaciando recipientes vacíos de aguas estancadas como llantas de desecho. 
C.2) Chinches. En este caso los hoteles usan mecanismos como la fumigación continua a lo largo del año. Sin embargo, ya había algunas técnicas desarrolladas para su control, como ordenar la ropa y revisarla, lavar toda la ropa de cama con agua caliente, alejar la cama de las paredes que es por donde suben a la misma, encerar o engrasar las patas de la cama para que no puedan subir por ella, en algunas ocasiones se informa que el uso de rellenar ranuras con diatomita sirve para matar a estos insectos y algunos otros donde el sílice rompe las membranas del tracto digestivo y causa problemas en el exoesqueleto.

En el caso de los Triatoma y Rhodnius el mejoramiento de la vivienda urbana como la educación sanitaria han sido factores de ayuda en el control. En estos casos la aplicación de fumigaciones es costosa y efectiva por unos meses nada más, y las mismas son costosas lo que evita que sean utilizadas. Hay estudios de control de estos chinches utilizando mecanismos de liberación lenta de organofosforados donde el efecto ha sido de hasta dos años (Oliveira-Filho 1997).

C.3) Ectoparásitos (ácaros). En este caso hay una serie de factores que afectan la transmisión y las poblaciones de estos organismos. En el caso de los Demodex se ha comprobado que viven asociados a la piel humana en los folículos de la piel, donde se alimentan de células muertas, aunque en algunos casos se asocia con la presencia de algunas lesiones de la piel como es la rosácea. La transmisión de estos ácaros a los niños se efectúa mediante el contacto de la piel en especial de la cara con el niño, como lo hacen los padres igualmente durante la lactancia materna puede darse la transmisión. Solo los recién nacidos no muestran presencia de estos ácaros.

Como es habitual estos ácaros no producen mayores molestias en los humanos por lo que no existen medidas se control sobre ellos, que estén dirigidas a su ataque. Se ha registrado que algunos factores culturales como es el género, la residencia, compartir cuidos sanitarios, la frecuencia de lavados de la cara al día y el uso de limpiadores faciales no correlaciona con las infestaciones de este ácaro en la piel (Zhao et al. 2011).

En el caso de la edad, las personas sobre 18 años presentan 22 veces más probabilidad de estar infestados con Demodex que las personas de 16 años de edad, los individuos entre 16-18 presentan 2 veces más posibilidades de infestación que los de edades 13-15 años, de igual manera la piel grasosa presenta 2 veces más posibilidades de infestación que la piel seca o neutra. Los individuos con problemas cutáneos presentan 3 veces más probabilidad de presentar infestaciones de este ácaro, de esta forma la dermatosis facial al incrementarse aumenta en paralelo con las poblaciones de ácaros en los folículos, como también hay relación con la presencia de acné (Zhao et al. 2011).

Es evidente que los factores culturales se asocian con la presencia de estos ácaros, incluyendo el cuido parental. Los factores culturales parecen no alterar los ciclos de vida de estas especies en forma negativa. Esto puede verse mediado por lo reducido de su tamaño y que las poblaciones se encuentran aisladas en los folículos de manera que se encuentran protegidas de los agentes externos.

Otro ectoparásito importante es Saroptes scabiei que produce la sarna de los humanos. En este caso esta especie se ve afectada en su prevalencia por conductas sociales y usos culturales. Por ejemplo, la sarna se trasmite por contacto directo con fómites (objetos no vivos que pueden ser de transporte a patógenos y parásitos). De esta forma el uso cultural de compartir pendas de ropa personales, como el uso de la misma ropa de cama sin ser lavada antes promueve el contagio de la sarna (Hay 2009). Por supuesto que el tiempo que logran sobrevivir estos organismos fuera del hospedero es un periodo corto y limitado. Los individuos aislados que no comparten prendas ni camas presentan menos probabilidad de infestación de este ácaro.

Esto indica claramente que los factores culturales y de comportamiento social pueden ser factores importantes en las infestaciones parasitarias, en este caso de ectoparásitos que 
pueden generar rechazo social en algunos grupos sociales. Esto convierte a estos organismos en noxas de varios tipos. La obvia noxa biológica que es el parásito en sí y la noxa social producida por la infestación lo que puede generar estrés e incluso puede llegar a estados depresivos de los individuos que padecen estas parasitosis, obligando a cambiar algunos hábitos de vida.

Con otros grupos de menor frecuencia como las coloradillas (Trombicúlidos) estos suelen aparecer con mayor frecuencia en algunas ocupaciones como agricultores o gente que trabaja en el campo como los guardaparques o los biólogos de campo que en las incursiones en los predios campestres se exponen a la infestación de este tipo de parásitos ocasionales. Un comportamiento similar se registra en las infestaciones por garrapatas. Como es evidente otro factor social importante es la ocupación la cual puede favorecer o tener un efecto protector sobre las infestaciones de algunos parásitos. De esta forma es menos probable hallar infestaciones de garrapatas o coloradillas en abogados que no tienen contacto con situaciones de vida silvestre.

C.4) Pulgas. Hay tres especies de pulgas fuertemente asociadas a las poblaciones humanas con factibilidad de ser recolectadas en seres humanos o animales peridomiciliares o que habitan con nosotros. Estas especies son Pulex irritans conocida como la pulga del humano, aunque no es específica de Homo sapiens y se puede encontrar en otros hospederos. Dos especies del género Ctenocephalides que se asocian a las mascotas más comunes de los hogares que son los gatos y los perros y en consecuencia presentan condiciones ambientales que favorecen que infesten al hombre. Por último, la especie Tunga penetrans que afecta a las poblaciones humanas en diferentes regiones del mundo.

En el caso de las pulgas los factores culturales son más complejos debido a que estos organismos como las moscas presentan ciclo de vida fraccionado en diferentes ambientes. De esta forma las pulgas son insectos parásitos de grupos en los que hay comportamiento nidícola debido a que la fase larval se desarrolla en el suelo o fuera del hospedero donde presentan una alimentación diferente a la del adulto. Esto dificulta que los adultos puedan mantenerse en los hospederos si hay un mínimo de normas de higiene como es el baño frecuente y el cambio de ropa de cama y personal.

El mantener a las mascotas aseadas afecta a las poblaciones de estos parásitos y se ha desarrollado toda una industria química alrededor de estos controles. Hay desde jabones y shampoos antipulgas hasta medicamentos de aplicación tópica o tomada que cortan el ciclo de vida de estos insectos. Este es un factor cultural importante que si bien controla a las pulgas también ejerce una presión de selección negativa sobre estas poblaciones promoviendo que haya poblaciones inmunizadas contra la aplicación de algunos de estos productos. De esta forma se registra un efecto similar al de los sistemas agrarios donde las poblaciones se van inmunizando contra el uso de estos químicos y al final es necesario el uso de productos cada vez más complejos y costosos para el control de estas especies de parásitos.

En el caso de los hematófagos ha sido necesario el desarrollo de desparasitantes que eran de uso exclusivo en veterinaria hace algunos años que se han dosificado para su uso en humanos. Este es el caso de la Ivermectina que se utilizaba en ganado vacuno y cerdos, luego se utilizó en mascotas casera y hoy se receta para combatir infecciones de nematodos intestinales, pero es útil también en el control de piojos, sarnas y las pulgas que se alimentan de sangre del hospedero.

Estos factores culturales se hacen cada vez más frecuentes para el desarrollo de poblaciones cada vez más resistentes a los controles desarrollados como un control de poblaciones de parásitos que pueden ser nocivas para los humanos. Estos desparasitantes pueden alterar también al hospedero debido a que estos pueden ser hepatotóxicos y rinotóxicos en muchos casos. 
Las pulgas necesitan un control integrado que lleve al control de adultos y formas larvales por separado. Esto puede causar diferentes sistemas de selección haciendo que unas poblaciones sean más resistentes que otras generando problemas regionales. Por otra parte, el desarrollo al aplicar métodos de control de poblaciones más difíciles de controlar lleva a problemas sociales.

El piquete de las pulgas puede llegar a infectarse si se rasca y se rompe el hospedero lo que causa problemas de la salud de la piel. Por otra parte, una persona que luce los brazos y cuellos con numerosos piquetes puede dar una sensación de insanidad y generar rechazo social de los compañeros de trabajo o de las personas que interaccionen frecuentemente con esta persona. Este factor cultural es importante debido a que en la época actual hay una menor tolerancia a las afecciones de la piel que puedan generar sospecha de padecimientos.

C.5) Piojos. El caso de las especies de piojos es similar al de las pulgas, llegando en algunos casos a necesitar el uso de lindano en el control de sus poblaciones. Sin embargo, el lindano es sumamente dañino al medio y también a la salud humana por lo que en algunos países se halla prohibida su aplicación y uso y ha sido necesario el desarrollo de estrategias de control de los parásitos.

Las formas de piojos que afectan al hombre directamente comúnmente son tres. El piojo de la cabeza que es de distribución cosmopolita, el piojo de la ropa más limitado en su distribución al Viejo Mundo y vector de importantes enfermedades para el humano y el piojo del pubis.

Los piojos necesitan de un contacto directo entre los hospederos para que sus poblaciones puedan infestar a otros miembros de la población. Por estos aprovechan momentos de contacto cercano. En especies que acostumbran a ser solitarias como los felinos la transmisión se da en momentos como la cópula o durante el cuido de las crías. En especies sociales los grupos de compañía favorecen la transmisión. Al vivir agrupados los individuos entran en contacto por juegos e interacciones entre ellos lo que facilita la transmisión de los piojos de un hospedero a otro.

Los piojos en términos generales no presentan sistemas de movilización que les permita un desplazamiento amplio hacia otros hospederos. Las especializaciones de este grupo lo obligan a mantenerse en su hospedero. De ahí que la transmisión se da solo por el contacto directo entre individuos. En estos casos la transmisión es muy limitada y las poblaciones son dependientes de sus hospederos. En estos casos los factores de comportamiento social son muy importantes en la distribución de las poblaciones de estos parásitos.

En el caso del piojo púbico (Pthirus pubis) se considera que su transmisión es de carácter sexual. Es decir, es considerado una enfermedad de transmisión sexual. Por la costumbre de los humanos de utilizar vestimenta el único momento en que las poblaciones de esta especie pueden entrar en contacto con otros hospederos es el momento de la cópula y los juegos asociados a esta donde hay posibilidades de generar puentes de pelo que permitan el paso de piojos de un individuo a otro. En EE.UU. se registran cerca de 3 millones de casos anuales de infestaciones con este insecto (Cullins 2016). En los últimos años hay una serie de informaciones que indican que la práctica de rasurado y depilado incrementa el riego de transmisión de enfermedades de transmisión sexual por efecto de la manipulación con instrumental que no se halla totalmente estéril aumentado el riesgo de transmisión de algunas enfermedades virales.

En los últimos años se han desarrollado modas que han actuado en contra de la presencia de estas poblaciones. En las clases sociales de mayor alcance económico se ha desarrollado la creencia de que la ausencia de vello corporal es un indicador de aseo, esto ha promovido la creación de técnicas de depilación o de rasurado que evitan que estas poblaciones de parásitos logren subsistir. Pero esto solo afecta a ciertas clases sociales. Las clases sociales que pueden y cuentan con los medios para poder seguir estas modas o estilos de vida y com- 
portamiento conducen a que las poblaciones de este parásito estén asociadas a poblaciones con menos recursos, menos acceso a sistemas de higiene y menor acceso a sistemas de comportamiento como es la depilación y el rasurado, con lo que los piojos púbicos empiezan a convertirse en un símbolo de estatus social bajo y poco aseo (Gewirtzman et al. 2011).

En el caso de los piojos de la ropa hay similitudes con las de las poblaciones de los piojos púbicos debido a que estos insectos (Pediculus humanus humanus) se hallan asociados a las costuras de la ropa, lo que los obliga a permanecer en la ropa para subsistir (Allen et al 2013). En las culturas donde el baño, el cambio de ropa y el lavado frecuente de las vestimentas como de la ropa interior promueve que las poblaciones se diezmen. Los piojos del cuerpo del humano son más frecuentes en el Viejo Mundo en donde muchas veces la escases de agua tenía como efecto directo una menor atención sobre el lavado de la ropa y en especial si esta debía lavarse con agua caliente de otra forma las poblaciones de piojos pueden subsistir en las costuras a pesar del lavado.

Algunas actividades humanas pueden favorecer estas poblaciones como es el caso de las guerras en donde los soldados no son capaces de mantener las condiciones de aseo necesarias en especial con respecto a las ropas lo que genera que la mínima infestación se convierta en una epidemia de piojos, favorecido por el hacinamiento de los sistemas de guerra. Esta forma asociada al cuerpo que se debate aún si es una especie diferente como se ha planteado varias veces en la historia, mantiene factores biológicos diferentes a la forma de la cabeza, con lo que hay diferencias en los grupos parasitados. Esta forma asociada al cuerpo se mantiene en la ropa. Oviposita en las costuras, es de mayor tamaño y pone mayor cantidad de huevecillos (Kim et al. 1986, Allen et 2013). Esta forma de piojo se ve limitada a ciertas poblaciones en algunas regiones del mundo y son poco frecuentes en las poblaciones neotropicales.

En el caso de los piojos de la cabeza la historia natural es diferente y los contagios también. Estas poblaciones de piojos (Pediculus humanus capitis) se ven afectadas por el comportamiento de los individuos afectados y es más habitual su contagio de la forma del cuerpo. Suelen incrementar las poblaciones en las épocas en las que empiezan los ciclos lectivos al incrementarse el contacto entre niños. La población infantil es más susceptible debido a que mantienen mayor contacto entre ellos en los juegos y otras actividades que en los adultos. En este caso el comportamiento favorece las infestaciones de este piojo en poblaciones juveniles. Esto ha sido planteado también recientemente como un factor que favorece la transmisión de estas poblaciones es el comportamiento de los adolescentes de acercarse mucho para hacer selfies (Molloy 2014).

\section{D) Barreras culturales y evidencias morfológicas de separación de formas en los Piojos de los humanos}

Los biólogos presentan la tendencia a sobrevalorar el concepto de alopatría donde la separación de las zonas donde se desarrolla una población puede influir fuertemente en la determinación de las especies. El concepto de alopatría fue descrito por Wallace (1855) en sus estudios de las variaciones de las mariposas de las Islas Borneo. Este concepto ha sido fundamental en la construcción del concepto de especie, de ahí que los biólogos y los taxónomos clásicos tengan problemas en aceptar el concepto de especiación simpátrica (Hendry 2009).

La contribución relativa de los diferentes modos de especiación puede evaluarse utilizando filogenias a nivel de especie con inclusión de la distribución geográfica de los adelphotaxa (Barraclough \& Nee 2001). En el caso de los animales de vida libre, el ámbito de las especies puede cambiar rápidamente, de tal manera que el ámbito observado podría no reflejar el modo de especiación real. En el caso de los parásitos la naturaleza de su estilo de vida relativamente invariable proporciona un marco de referencia más directo y exacto para 
el estudio de los procesos de especiación. En los casos en los que se registra coespeciación filogenética entre las especies de parásitos y las especies de los hospederos puede conducir a que, dado que los parásitos dependen de sus hospederos, es probable que la especiación en este último induzca la especiación en el parásito, dando lugar a filogenias de imagen especular lo que constituye la denominada regla de Fahrenholz (Brooks 1979). Por otra parte, un tercer fenómeno, la especiación simpátrica, ha ganado reconocimiento como modo de especiación alternativo, operando bajo circunstancias específicas (Huyse et al. 2003).

Los parásitos no siempre deben considerarse miembros "pasivos" en una asociación; algunos taxa pueden también moverse independientemente de sus hospederos y esto puede llevarlos a cambiar activamente los anfitriones. Mientras que la co-especiación puede considerarse como especiación alopátrica vicariante, la conmutación del hospedero puede considerarse como especiación peripátrica o de aislamiento periférico (Brooks \& McLennan 1993). Este es posiblemente en fenómeno registrado en los piojos de los humanos.

En el caso de los piojos de los humanos no hay una correspondencia filogenética entre la filogenia de los hospederos y la de los piojos que los habitan, por lo que no existe una coespeciación directa sino mediada por factores ecológicos de asociación que han producido algunos procesos de especiación debida al aislamiento de los hospederos (Retana-Salazar 1996). Esto se ve confirmado por la capacidad de los piojos humanos de alimentarse de otras especies de esta forma para mantener poblaciones en laboratorio se pueden alimentar en conejos, los cuales son filogenéticamente muy lejanos de los humanos y los primates, lo que indica que las relaciones deben ser ecológicas.

Las formas que se han registrado en los piojos y de las cuales hay numerosas sinonimias pueden ser mediadas por aislamiento ecológico. Encontrar formas intermedias como se ha argumentado en el caso de la forma de la cabeza y la del cuerpo ha evitado que se diferencien como especies. No obstante, hay una serie de caracteres morfológicos y genéticos que separan a las poblaciones con claridad, pero los taxónomos clásicos prefieren mantener una única especie a pesar de las evidencias de comportamiento, de oviposición y morfológicas (Light et al. 2008, Allen et al. 2013). Otros especialistas han preferido proponer segregaciones que reflejen estas realidades biológicas (Retana-Salazar 2006).

Al respecto, Zumpt (1966) en su discusión acerca de la validez de la forma Pediculus humanus maculatus establece que entre las dificultades para establecer los límites morfológicos de las formas de los piojos asociadas a humanos depende en gran medida del traslape de las poblaciones que evitan una clara diferenciación de caracteres. Este argumento se ha utilizado muchas veces para validar el mantener a los piojos de la cabeza y del cuerpo como la misma especie (Ferris 1951), lo que es una posición clásica de los taxónomos del grupo. Es una posición cómoda desde el punto de vista de la clasificación establecer que las variaciones no permiten establecer límites claros de las diferentes formas. El avance de las técnicas taxonómicas indica que las especies obedecen a más criterios que los simples argumentos de aislamiento, pero si debe tomarse en cuenta que las poblaciones de algunas etnias al mantenerse aisladas promueven la fijación de caracteres particulares que pueden favorecer la formación de especies nuevas.

Uno de los objetivos de este trabajo es analizar como los comportamientos de las poblaciones hospederas pueden ser una presión de selección sobre las poblaciones de piojos. En las escuelas el juego constante de los niños provoca un contacto directo con el pelo de unos con otros. Este puente de pelo favorece la infestación de un niño a otro. Esto es complejo en los humanos adultos, aunque en acercamientos entre personas donde el pelo puede entrar en contacto puede favorecer el paso de los piojos de un individuo a otro.

En años recientes ha habido un incremento de las poblaciones de este piojo en adolescentes en EE.UU. Ante esto se ha argumentado que algunos comportamientos que han desarrollado los adolescentes pueden favorecen el puente de pelo necesario para la infestación de piojos. Entre estas razones que se han propuesto está la esgrimida por la Dra. McQuillan 
acerca de cómo el comportamiento social de los adolescentes al tomar selfies facilita la infestación de piojos entre ellos (Molloy 2014).

$\mathrm{El}$ incremento de medidas de control contra las poblaciones de piojos ha incrementado la resistencia de estos insectos a los mecanismos de control. Se registra en los EE.UU. que las poblaciones de piojos de al menos 25 estados son resistentes a los tratamientos convencionales para el control de las poblaciones de piojos (Oaklander 2015). Estudios de genética molecular han determinado que hay una fuerte selección sobre las poblaciones de piojos en EE.UU que han hecho que estas sean resistentes a los controles generales de los piojos (Yoon et al. 2014). De esta forma los factores culturales de estudio pueden afectar los factores biológicos de las poblaciones de estos insectos causando presiones de selección fuertes que cambian la estructura genética y eventualmente la morfología de las poblaciones.

Estos factores socio-culturales que afectan los procesos de selección de las poblaciones no deben ser desestimados de los procesos de microevolución que pueden afectar luego procesos de macroevolución que pueden dar origen a nuevos morfotipos en las poblaciones lo cual puede alterar los procesos de especiación de los parásitos (Huyse et al 2003). Sin embargo, hay comportamientos culturales de las etnias que pueden afectar la fijación de caracteres morfológicos más evidentes en las poblaciones.

Recientemente Retana-Salazar \& Rodríguez-Arrieta (2016) ha descrito una serie de variaciones estructurales incluyendo las de la genitalia de las poblaciones de piojos asociadas a diferentes hospederos e incluso dentro de las poblaciones de los morfotipos que afectan a los humanos en diferentes regiones del mundo. Sin embrago, los estudios coevolutivos de estos piojos con relación a sus hospederos son muy limitados (Retana-Salazar 1996) y en los casos donde se utilizan filogenias moleculares se subestiman las relaciones de las formas que han sido consideradas sinonimias, con lo que las decisiones taxonómicas afectan los resultados obtenidos. Un análisis que incluya un mayor número de formas sería mucho más representativo que estos trabajos de baja muestra efectuados con algunos datos moleculares, como los que se han publicado en las últimas décadas como es el caso de Reed y colaboradores (2007).

D.1) Variaciones, poblaciones y etnias. En algunos parásitos se ha demostrado que hay una separación de linajes en las poblaciones humanas que afectan, como sucede en Cimex lectularius, donde la evidencia publicada previamente de diferenciación morfológica y conductual, se ajustan a los datos hallados en otros trabajos sobre la genética de la especie que sugieren que $C$. lectularius está experimentando actualmente una divergencia de linajes a través de la asociación con el hospedero (Booth et al. 2015). En los piojos puede estar sucediendo algo similar, pero no hay estudios que indiquen esto con claridad. Solo hay estudios que indican que variaciones moleculares dependiendo de la distribución geográfica, lo que podría indicar la separación de linajes de la misma forma.

A pesar de las diferencias entre los piojos del cuerpo y de la cabeza se argumenta que la forma que parasita el cuerpo es la misma especie que la de la cabeza a pesar de sus diferencias biológicas y ecológicas debido a que los datos moleculares indican que una surge de la otra (Allen et al. 2013) lo cual es normal en los procesos de especiación, que una especie tenga origen en otra. Lo que no es común es que como se ha sugerido la forma del cuerpo surja indistintamente varias veces en la historia evolutiva a partir de las poblaciones de piojos de la cabeza. Este tema ha sido de amplia discusión en la literatura, pero algunos grupos prefieren ignorar las hipótesis planteadas por otros investigadores que no concuerdan con las presentadas desde los estudios moleculares, pero esto debe ser analizado en otros estudios.

Aquí se analiza el caso de las variaciones morfológicas de las formas de piojos del género Pediculus en asociación con diferentes hospederos y con diferentes comportamientos, donde se evidencia que el aislamiento étnico puede ayudar a procesos de especiación como 
ha sucedido en otros casos donde se ha dado especiación por efecto del comportamiento humano (Hendry 2009).

Ferris (1951) sinonimiza una serie de formas de piojos que considera la misma especie que el piojo de la cabeza de los humanos, esto en función de una morfología conservada y de una genitalia poco variable. Este autor no consideró las variaciones de las estructuras accesorias de las hembras que en algunos casos han sido de utilidad en la separación de especies.

No obstante, este autor reconoce que hay una especie del género Pediculus asociada a los chimpancés, otra asociada al humano en la que se diferencian dos formas la de la cabeza y la del cuerpo que algunos consideramos como especies aparate, una especie asociada a los monos del Nuevo Mundo y por último reconoce que existe la especie descrita por Ewing (1938) como Pediculus pseudohumanus a partir de material recolectado en un mono muerto Pithecia monachus. Se informa de la presencia de esta especie de piojo en Cacajo rubicundus de la Alta Amazonía, al parecer la forma es de distribución amplia en América del Sur, pero de poca frecuencia en su recolecta.

Al analizar muestras de poblaciones humanas se ha encontrado esta especie en habitantes de las islas Marquezas (Pacífico Sur) (Ferris 1951) y de otras etnias continentales. También se han hallado evidencias de esta especie en poblaciones de indígenas de Chile de 3000 años de antigüedad. Esta forma parece estar bien distribuida y presenta un claro intercambio entre humanos y primates en el Nuevo Mundo, quizás por el contacto entre algunas poblaciones de los humanos y algunos hospederos de los primates del Nuevo Mundo.

Los estudios de Retana-Salazar (2005) han mostrado como se pudo dar la colonización de los humanos al continente americano ingresando también por el cono sur como ha sido propuesto en recientes trabajos de investigación molecular que indican que el ingreso de las poblaciones humanas en América no coincide exclusivamente con un ingreso por el Estrecho de Bering (Raghavan et al. 2014). Las trazas morfológicas de los piojos pueden funcionar como marcadores importantes de las poblaciones y su aislamiento, y su distribución al ser comparada con los resultados de las filogenias morfológicas de un espectro de formas más amplio que el incluido en las filogenias moleculares, indica que es posible que estas formas ya existieran y llegaran con el Homo sapiens a América provenientes de las poblaciones aisladas de las Polinesias, de donde infestaron a los piojos del Nuevo Mundo (Retana-Salazar 2005).

Kim \& Ludwig (1978) consideran a todas estas especies como sinónimos de Pediculus humanus y esta posición ha sido formalmente aceptada por los demás especialistas dejando por fuera consideraciones de las variaciones morfológicas que se han justificado como parte de la alta variabilidad de Pediculus humanus. Se ha reconocido en los últimos años a las especies de los Monos del Nuevo Mundo como válidas donde se registran dos especies Pediculus mjobergi y Pediculus mendezi, sin embargo, las formas como Pediculus friedenthali asociada a los gibones del Viejo Mundo no ha sido reconocida y se considera como una sinonimia de $P$. humanus a pesar de que las hembras presentan caracteres de la setotaxia de los gonopodios que es característica de esta forma y no se presenta en $P$. humanus (RetanaSalazar 2006).

Light y colaboradores (2008) analizan el problema y consideran que es mejor mantener todas las formas en una especie a juzgar por los resultados moleculares contradictorios obtenidos mientras que Allen y colaboradores (2013) consideran que los estudios moleculares son claros y que se trata de una sola especie. Algunas de las debilidades de estos trabajos son: a) baja muestra de las diferentes formas, nunca se considera a las poblaciones de gibones o atélidos, los datos moleculares son obtenidos solo de especímenes tomados de humanos en diferentes regiones del mundo donde las muestras de América Latina son escasas en especial las de América Central, b) hay un sesgo claro de la posición de los taxónomos que asume a todas las formas como la misma, lo que hace que los biólogos moleculares conside- 
ren solo las poblaciones humanas como fuente de material de estudio, cuando debería analizarse las poblaciones de todos los hospederos posibles, c) no hay revisiones taxonómicas de los grupos desde el punto de vista morfológico, solo análisis moleculares, el trabajo de Retana-Salazar (2006) sobre la revisión de este grupo es poco divulgado y no se han hecho análisis moleculares de las formas estimadas por este autor, d) no se ha analizado el aislamiento de las poblaciones humanas y su efecto sobre las poblaciones de piojos, que es parte de la idea del presente estudio, e) se desestiman las evidencias morfológicas y ecológicas de las diferentes formas priorizando solo los resultados moleculares que han sido producto de pocas muestras solo de agrupaciones humanas, la mayor parte de ellas se sitios urbanos de alta densidad de población de humanos.

D.2) Pediculus humanus y sus formas asociadas a grupos étnicos particulares. La diferenciación de formas en los piojos asociados a las poblaciones humanas ha sido un tema de discusión de larga data (Ferris 1951). Retana-Salazar (2006) hace un recuento de las formas que fueron sinonimizadas en los últimos años desde Ferris (1951).

Las formas intermedias entre morfologías extremas han generado que los taxónomos clásicos consideren a todas las formas o especies que se han descrito baja un único nombre en las poblaciones humanas, con dos formas que si bien presentan una serie de caracteres diferenciales molecularmente no son fácilmente separables por lo que utilizando este criterio como fundamental algunos especialistas han considerado todas las formas como variaciones de una especie (Allen et al. 2013). Esto evidentemente proporciona una enorme facilidad de trabajo evitando las comparaciones con segregados morfológicos diferentes. La única revisión taxonómica formal en la que se analiza material de las colecciones de museo no coincide con estos resultados (Retana-Salazar 2006), pero por tratarse de datos morfológicos este trabajo no ha sido ampliamente divulgado.

La discusión ha sido amplia y los moleculares la consideran finalizada. No obstante, las relaciones de estos parásitos con las poblaciones humanas son más compleja de lo que se logra exponer a través de unos pocos datos moleculares de unas cuantas poblaciones de piojos. Uno de los factores que se desestima son los factores antropológicos que caracterizan el comportamiento humano y su distribución.

Para los humanos ha sido imposible obviar las diferencias que se registran entre los miembros de diferentes poblaciones humanas. Esto condujo a crear el concepto antropológico de raza utilizado en los siglos XVII-XX. Esta posición que era una argumentación de la Antropología Física ha cambiado y se ha ampliado el ámbito de estudio de las poblaciones humanas creando la Antropología Biológica. Estas disciplinas estudian los cambios de las poblaciones humanas con dos diferentes enfoques. La Antropología Física como lo dice su nombre establece las diferencias en función de caracteres morfológicos como el color de la piel, el tipo de pelo, la estatura entre otros. La Antropología Biológica ha dejado de lado estas consideraciones morfológicas y ha conducido el estudio hacia las variaciones en las poblaciones estudiadas a través de la genética de poblaciones humanas. Ninguno de los dos enfoques es global.

El hecho es que hay poblaciones que mantienen una serie de características que son particulares de esas poblaciones. Esto era más evidente antes de la rápida globalización que ha permitido la mezcla de poblaciones de todas partes del mundo, homogeneizando las características poblacionales. Sin embargo, aún quedan algunos relictos que permiten establecer diferencias en las poblaciones. Uno de estos casos son los Bushmen de África (también llamados San), esto sucede también con los pigmeos y otra serie de etnias en el mundo. Esto se registra también en las poblaciones relictuales de los aborígenes americanos. Estos grupos étnicos con poco contacto con otros grupos humanos por sus usos culturales y sistemas de creencias y de sus formas de vida. Estos factores antropológicos y sociales permiten el desarrollo de barreras culturales entre los pueblos que no se han evaluado en sus efectos sobre 
las poblaciones de parásitos con profundidad y en el caso de los piojos han sido dejadas de lado.

Zumpt (1966) establece que su estudio de material recolectado en Bushmen en el año 1963, permite diferenciar con claridad esta forma de piojo en relación con las otras dos formas ubicadas en humanos. Este autor propone restablecer el uso de la forma Pediculus humanus maculatus en base a sus observaciones relativas a la morfología de las poblaciones de piojos. No obstante, en la literatura han prevalecido los argumentos de Ferris (1951) acerca de las formas intermedias como evidencia de flujo genético que no permite separar estas formas. El mismo argumento se ha utilizado con las formas que parasitan a otras especies como es el caso de los gibones o los monos del Nuevo Mundo, en estos últimos se han aceptado dos especies que han sido muy poco estudiadas. Estas formas no han sido nunca analizadas desde un punto de vista molecular lo que posiblemente sería necesario para poder comparar con los datos de Pediculus humanus capitis y Pediculus humanus humanus. En la actualidad sabemos que las barreras de flujo genético no son un determinante de la existencia o no de las especies debido a que estas son linajes con una historia evolutiva, que es el concepto moderno de especie (Hendry 2009).

Se ha documentado a través de estudios morfológicos de los piojos asociados a poblaciones humanas que hay linajes claramente caracterizados por marcadores morfológicos y que estos pueden o no mostrar variaciones moleculares (Retana-Salazar 2006). Además, que las variaciones de las estructuras genitales de los machos y las hembras indican que hay poblaciones aisladas con caracteres que se han fijado y son reconocibles, lo que indica la necesidad de reevaluar los criterios utilizados en la separación de estas formas (RetanaSalazar \& Rodríguez-Arrieta 2016).

En este aspecto ha sido revelador algunos estudios recientes acerca de la compatibilidad de los estudios de filogenia molecular y los de morfología donde Kjer y colaboradores (2016) analizan que en numerosos estudios se ha observado que los datos de filogenias moleculares en ausencia de datos morfológicos no son conducentes a buenos resultados, este es el caso de las filogenias de insectos presentadas por Wheeler basadas solo en datos moleculares donde la ausencia de datos morfológicos condujo estos resultados a filogenias no resueltas y con asociaciones no plausibles. Esto mismo puede estar sucediendo en el caso de los piojos de los humanos por falta de estudios morfológicos en concordancia con los datos moleculares. El mayor problema de esto es la necesidad de los muestreos en animales silvestres para obtener muestras que permitan obtener un verdadero panorama de la realidad genética de las poblaciones de piojos y no mantener estos datos limitados a las poblaciones de piojos asociadas a las poblaciones humanas de las grandes urbes.

Aparte del caso descrito por Zumpt (1966), se pueden identificar formas caracterizables de piojos en etnias de América del Sur y de América Central. En estudios conducidos desde el año 2010 se ha podido determinar que en las poblaciones de las etnias Bribri y Ngobe de Costa Rica y Panamá se localizan series de piojos que presentan los caracteres descritos por Ewing (1938) al describir la especie Pediculus pseudohumanus, estos mismos caracteres se registran en piojos de otras etnias como los Mayas de Guatemala y los piojos hallados en las momias Chinchorro donde concuerdan con estos caracteres, tanto los caracteres de los piojos adultos como los caracteres derivados del huevecillo que fue descrito por Ewing (1938). Ferris (1951) no sinonimiza la especie $P$. pseudohumanus debido a que considera que sus variaciones son suficientes como para considerarla una especie aparte, este autor registra esta especie en humanos de las Islas Marquezas, sin embargo, trabajos posteriores han considerado a esta especie como una forma más sinónima de $P$. humanus (Kim \& Ludwig 1978). Retana-Salazar \& Rodríguez-Arrieta (2016) muestran en un estudio comprensivo de los caracteres asociados a la genitalia de diferentes formas de piojos asociados a humanos y monos del Nuevo Mundo que hay una serie de caracteres que identifican a las especies de los piojos del Nuevo Mundo y entre ellas a $P$. psedohumanus, por lo que esta debería 
considerarse una especie válida.

Este morfotipo de piojo asociado a poblaciones humanas se halla restringido a poblaciones de monos del Nuevo Mundo y a poblaciones humanas residentes que se registran desde Chile hasta Guatemala en especial en el litoral Pacífico del Continente. Los estudios con CO1 indican que las diferencias entre las secuencias de estos especímenes y los de los piojos de la cabeza registrados en las bases de datos internacionales se diferencian entre 1-2\% lo que indica que hay una clara separación de los linajes que está aún en proceso. Esta forma indicada por Ferris (1951) como perteneciente a individuos de las Islas del Pacífico Sur y de América del Sur en etapas anteriores a la colonia indican que esta forma pudo haber llegado al continente mediante poblaciones de las Polinesias que alcanzaron las costas del continente (Retana-Salazar 2005).

El aislamiento y las costumbres todavía hoy existentes de los pueblos aborígenes americanos son un factor fundamental en que se mantengan las poblaciones aisladas de sus formas de piojos, las cuales son perfectamente reconocibles por su morfología, como fue propuesto por investigadores de principio de siglo. Los pueblos Ngobe y los Bribri actuales consideran que los piojos mantienen parte de la identidad del hospedero por alimentarse de su sangre. Esto ha llevado a que las poblaciones sean incluso protegidas de los sistemas de recolección. Además, la estructura social de estos grupos étnicos no permite que cualquier investigador tenga acceso libre a las muestras, lo que ha dificultado la obtención de datos de este tipo de poblaciones. Los datos moleculares que hay disponibles no se han publicado y en este trabajo se hace la primera mención de los mismos como parte de un proyecto de investigación formal de la Universidad de Costa Rica.

Hendry (2009) establece que hay factores del comportamiento humano que pueden afectar tanto la separación de poblaciones produciendo procesos de diferenciación y hasta especiación, como también se ha favorecido que las poblaciones al ponerse en contacto por efecto de los disturbios ambientales se genera la posibilidad de que aquellas especies que no han tenido la necesidad de crear barreras de aislamiento entre ellas por el aislamiento ecológico, lleguen a presentar un flujo de genes que no se registraba antes homogenizando las poblaciones.

Es evidente que los factores antropológicos y culturales afectan las especies y entre ellas las de parásitos asociados a las poblaciones humanas. De ahí la importancia de valorar el entorno y las relaciones de las poblaciones humanas en relación de como los factores antropogénicos pueden ser fundamentales en la comprensión de los procesos biológicos de las especies que nos afectan o que utilizamos cotidianamente.

\section{Conclusión}

Las modernas tendencias de análisis indican que hay una clara relación entre los factores biológicos y socio-culturales, de manera que la historia biológica de las poblaciones humanas se ve claramente vinculada al desarrollo histórico del Homo sapiens como protagonista de su trayecto a lo largo de la historia de las culturas. Nuestras sociedades no distan mucho de las de los neandertales o los chimpancés en sus constructos fundamentales de vinculaciones, y estos factores no cambian seriamente en grupos pequeños, pero cambiamos seriamente de actitud cuando nos reunimos en grupos de conciliación como sucede en los organismos internacionales o los congresos de los países donde el agrupamiento conduce a la búsqueda de factores de acuerdo (Harari 2016).

Uno de los grandes factores que ha diferenciado el desarrollo humano del de otras especies de primates que mantienen incluso una similitud enorme con nosotros desde el punto de vista molecular pero no desde el punto de vista morfológico y cognitivo en donde las diferencias mantienen medidas diferentes y debe utilizarse otras escalas. Los estudios moleculares indican que la diferencia entre el chimpancé y el humano a nivel genético alcanzan 
un nivel de 1,24\% (Chen \& Li 2001) lo cual es menos de lo que se justifica para la separación de especies desde el punto de vista molecular. La distancia entre los piojos de este trabajo en las secuencias de CO1 es de cerca del $2 \%$ y los especialistas se niegan a aceptar que sea suficiente para separar las especies de piojos, pero un escaso $1 \%$ de diferencia entre humanos y chimpancés es más que suficiente para marcar diferencias muy evidentes. Las diferencias entre especies no pueden medirse solo por sus distancias moleculares, las cuales pueden verse alteradas por el gen que se estudie entre otras razones.

Los parásitos no son una excepción a los sistemas socio-culturales y su percepción social puede afectar sus poblaciones de varias formas. Los parásitos como tales entran dentro de la común definición de las noxas biológicas que incluyen a los virus, bacterias y demás patógenos como a las especies parásitas del humano como son los hongos, algunos nematodos y algunas especies de artrópodos. Sin embargo, las reacciones de los grupos sociales ante la población que se ve afectada por un parásito genera una noxa social que se suma al problema biológico y clínico de la noxa biológica.

Esta noxa social puede llegar a tener implicaciones legales directas dependiendo del marco legal de cada país. De esta forma el despiojar a un niño en las escuelas de algunos países de América Latine puede ser un caso de discriminación porque está causando un problema de segregación a los niños con piojos. Por otra parte, la noxa social puede conducir a problemas en la determinación y solución de un problema de salud, cuando los individuos de un grupo que siente que será estigmatizado cuando se dé a conocer que tienen un problema relativo a una infestación parasitaria, por lo que los individuos afectado tratan de manejar este problema sin recurrir a los profesionales en salud. Esto además no facilita llevar los registros exactos de la epidemiología parasitaria.

Las parasitosis se ven afectadas por patrones sociales, pero de igual forma la presencia de parasitosis en especial las externas que suelen ser más evidentes en las personas afectadas, pueden generar reacciones del grupo social que aíslen o segreguen a los individuos afectados por los parásitos. Hay una doble vía entre el factor biológico puramente de la parasitosis que puede verse favorecida o limitada por factores sociales de comportamiento o usos culturales, en algunos casos estos usos culturales derivan de respuestas a condiciones ambientales en las que se han desarrollado las diferentes poblaciones humanas y el efecto de las parasitosis en el comportamiento social de los afectados según sea el caso de cada una de las poblaciones humanas y sus costumbres. Así, por ejemplo, se han registrado casos en los que algunos individuos no gustan de ser despiojados, en especial si se trata de piojos púbicos por un gusto desarrollado por el prurito generado por los piojos del pubis en esta región corporal.

En una sociedad como la nuestra en la que se le da un valor particular a la higiene corporal cualquier factor ambiental que haga dudar de esta condición en un individuo del grupo provoca una reacción inmediata de segregación por parte de otros miembros del grupo social. A esto se suma que la falta de higiene se asocia también con el estatus económico de los individuos con lo que la falta de higiene puede interpretarse como propia de individuos con pocos recursos y en consecuencia pertenecientes a grupos estigmatizados como son los grupos de extrema pobreza, los indigentes y los drogadictos sin hogar que habitan las calles entre otros.

El que los humanos sigamos trayectorias definidas de nuestra historia tan diferentes y marcadas obviamente por factores sociales y culturales nos lleva a que las presiones que ejercemos sobre otras especies sean diferentes a las que ejercen sistemas naturales sobre las especies, esto nos obliga a contemplar una nueva dimensión de las poblaciones humanas sobre las poblaciones de otras especies a las que afectamos desde el punto de vista cultural. Se ha evidenciado que las presiones de los humanos sobre algunas poblaciones de animales y otras especies provoca un cambio selectivo más rápido en estas que en aquellas que no hay este tipo de presiones de las poblaciones humanas, lo que tiene una obvia consecuencia en 
los factores de desarrollo evolutivo de estas poblaciones (Stenseth \& Dunlop 2009). Esto se ha registrado también en poblaciones de insectos que mantienen una estrecha relación parasitaria con los humanos como es el caso citado de Cimex lectularius donde hay divergencia de los linajes genéticos asociados a las poblaciones de los humanos generando una presión de selección (Booth et al. 2015). Se ha establecido que esta especie de amplia distribución entre humanos mantiene como hospedero también a algunas especies de murciélagos y se consideran la misma especie a pesar de la separación de hábitats y conductas de las poblaciones de humanos y de murciélagos.

Recientes estudios han demostrado que las poblaciones de Cimex lectularius asociadas a humanos como las poblaciones asociadas a murciélagos muestran claras diferencias moleculares y también los estudios morfométricos existentes indican que hay diferencias morfológicas que se pueden registrar entre ambas poblaciones, lo que parece indicar que hay diferenciación de las poblaciones y posible especiación simpátrica (Balvín et al. 2012). Un caso similar puede estar sucediendo en las poblaciones de piojos de los humanos, donde los datos morfológicos indican diferencias entre poblaciones lo cual se ha documentado ampliamente en la literatura (Busvine 1944, 1978, Retana-Salazar \& Ramírez-Morales 2006). El problema radica en las bajas muestras de estudio de las poblaciones de piojos en las poblaciones humanas. Mientras los datos de Leo y colaboradores (2005) indican que las poblaciones de piojos de 11 casos de humanos de doble infestación con microsatélites de DNA indican que los piojos del cuerpo y de la cabeza son molecularmente dos especies diferentes, lo cual ha sido refutado en la literatura como un dato inconveniente por múltiples razones (Light et al. 2008). También podemos encontrar publicaciones con menos muestra (tan solo 5 individuos de las calles de París) muestran que el genotipo de los piojos de la cabeza y del cuerpo son similares (Veracx et al. 2012). Estos resultados contradictorios presentan algunos inconvenientes como el tipo de datos moleculares utilizados y el tamaño de la muestra y la correcta identificación de los piojos de la cabeza y el cuerpo que pueden haber sido clasificados de forma equivocada.

A pesar de las evidencias derivadas de otros análisis como la distancia filogenética, análisis morfométricos y cladísticos entre otros las propuestas de cambios taxonómicos no se han validado debido a que los datos moleculares se hallan rezagados en una conceptualización en la que se desestima el factor de las poblaciones humanas sobre las poblaciones de los parásitos. Esto sucede en el caso de los piojos lo cual no se registra en otros grupos de parásitos donde los estudios se efectúan de manera más amplia por equipos más numerosos. Este es un ejemplo de cómo los grupos más numerosos pueden ayudar que haya un avance mayor de las evidencias que aquellos en que hay pequeños grupos de investigadores cerrados sobre una idea y que al no haber más grupos de estudio, se produce un grupo cerrado que solo acepta sus ideas y se cierra a nuevas fronteras lo cual es común en los grupos sociales donde los prejuicios cognitivos de autoridad pueden sesgar y hasta atrasar el desarrollo de nuevas ideas.

\section{Agradecimientos}

Se agradece al personal administrativo y docente del Centro de Investigación en Estructuras Microscópicas (CIEMIC) por sus aportes y respaldo en el desarrollo de estas iniciativas de investigación. En especial a Said Retana-Salazar y Alexander Rodríguez-Arrieta por las largas discusiones que han enriquecido estos temas. A la Vicerrectoría de Investigación por el apoyo financiero para el desarrollo de estas actividades de investigación.

\section{Bibliografía}

ALLEN, J.M., WORMAN, C.O., LIGTH, J.E. \& REED, D.L.

2013 Parasitic Lice Help to Fill in the Gaps of Early Hominid History. In: F. Brinkworth \& K. 
Pechenkina (eds.), Primates, Pathogens, and Evolution, Developments in Primatology: Progress and Prospects, DOI 10.1007/978-1-4614-7181-3_6.

BALVIN, O., MUNCLINGER, P., KRATOCHVIL, L. \& VILIMOVA, J.

2012 Mitochondrial DNA and morphology show independent evolutionary histories of bedbug Cimex lectularius (Heteroptera: Cimicidae) on bats and humans. Parasitology Research DOI 10.1007/s00436-012-2862-5

BARRACLOUGH, T.G. \& NEE, S.

$2001 \quad$ Phylogenetics and speciation. Trends Ecology and Evolution 16:391-399.

BOOTH, W., BALVIN, O., VARGO, E.L., VILIMOVA, J. \& SCHAL, C.

2015 Host association drives genetic divergence in the bed bug, Cimex lectularius. Molecular Ecology 24(5):980-92. doi: 10.1111/mec.13086.

BROOKS, D.R.

1979 Testing the Context and Extent of Host-Parasite Coevolution. Systematic Zoology 28:299307.

BROOKS, D.R. \& MCLENNAN, D.A.

1993 Parascript. Parasites and the Language of Evolution, Smithsonian Institution Press, Washington/London.

BUSVINE, J.R.

1944 Simple experiments on the behaviour of body lice (Siphunculata). Proceedings of the Royal Entomological Society of London 19:22-26.

BUSVINE, J.R.

1978 Evidence from double infestions for the specific status of human head liece and body lice (Anoplura). Systematic Entomology 3:1-8.

BUSWELL, J.M., MOLES, A.T. \& HARTLEY, S.

2011 Is rapid evolution common in introduced plant species? Journal of Ecology 99:214-224

CALDERÓN, O. \& SÁNCHEZ, C.

1996 Variabilidad morfológica en tres cepas de Sarcoptes scabiei (Acaridida: Sarcoptidae) de CULLINS, V. Costa Rica. Revista de Biología Tropical 44(2):679-682.

2016 Pubic Lice. Planned Parenthood. https://www.plannedparenthood.org/learn/stds-hiv-safer-sex/pubic-lice consultado 24/12/2016.

EWING, H. E.

1938 The Sucking Lice of American Monkeys. The Journal of Parasitology

24(1):13-33.

DEEM, S.L., BLAKE, S., MILLER, R.E. \& PARKER, P.G.

2010 Unnatural Selection in Galapagos: The Role of Disease in Darwin's Finches (Geospizinae). Galapagos Research 67:62-64.

DEUTSCH, C.A., TEWKSBURY, J.J., HUEY, R.B., SHELDON, K.S., GHALAMBOR, C.K., HAAK, D.C. \& MARTIN, P.R.

2008 Impacts of climate warming on terrestrial ectotherms across latitude. PNAS 105(18): 6668-6672.

FERRIS, G. W.

1951 The Sucking Lice. Pacific Coast Entomological Society. Memoirs 1:320pp.

GEWIRTZMAN, A., BOBRICK, L., CONNER, K. \& TYRING, S.K.

2011 Epidemiology of Sexually Transmitted Infections. In: G. Gross and S.K. Tyring (eds.), Sexually Transmitted Infections and Sexually Transmitted Diseases, 13, DOI: 10.1007/9783-642-14663-3_2

HARARI, Y.N.

2016 Sapiens. De animales a Dioses. 6ta ed. Debate. Madrid, España, 493pp.

HAY, R.J.

2009 Scabies and pyodermas-diagnosis and treatment. Dermatologic Therapy 22(6):466-474.

HENDRY, A. P.

2009 Speciation. Nature 458:162-164.

HENDRY, A.P., GRANT, P.R., GRANT, B.R., FORD, H.A., BREWER, M.J. \& PODOS, J.

2006 Possible human impacts on adaptive radiation: beak size bimodality in Darwin's finches. 
Procedings of the Royal Society of London B Biological Sciences (published online) doi:10.1098/rspb.

HUYSE, T., AUDENAERT, V. \& VOLCKAERT, F.A.M.

2003 Speciation and host-parasite relationships in the parasite genus Gyrodactylus (Monogenea, Platyhelminthes) infecting gobies of the genus Pomatoschistus (Gobiidae, Teleostei). International Journal for Parasitology 33:1679-1689.

JUSTICE, S.S., HUNSTAD, D.A., CEGELSKI, L. \& HULTGREN, S.J.

2008 Morphological plasticity as a bacterial survival strategy. Nature Reviews. Microbiology. 6(2):162-168.

KIM, K. C. \& LUDWIG, H. W.

1978 The family classification of the Anoplura. Systematic Entomology 3:249-284.

KIM, K. C., PRATT, H. D. \& STOJANOVICH, C. J.

1986 The sucking lice of North America. An Illustrated manual for identificaction. Pennsylvania State University Press 241pp.

KJER, K.M., SIMON, C., YAVORSKAYA, M. \& BEUTEL, R.G.

2016 Progress, pitfalls and parallel universes: a history of insect phylogenetics. Journal of The Royal Society Interface 13:2016.0363.

LEO, N.P., HUGHES, J.M., YANG, X., POUDEL, S.K.S., BROGDON, W.G. \& BARKER, S.C.

2005 The head and body lice of humans are genetically distinct (Insecta: Phthiraptera, Pediculidae): evidence from double infestations. Heredity 95:34-40 doi:10.1038/sj.hdy.6800663.

LIGHT, J. E., TOUPS, M. A. \& REED, D. L.

2008 What's in a name: The taxonomic status of human head and body lice. Molecular Phylogenetics and Evolution 47:1203-1216.

MACMILLAN, A.

2000 Mauritius Illustrated: Historical and Descriptive, Commercial and Industrial Facts, Figures, \& Resources. Asian Educational Services. pp. 83.

MINISTERIO DE SALUD PÚBLICA DE URUGUAY.

2011 Manual de Vigilancia y Control de Aedes aegypti. Dirección General de Salud, División de Epidemiología/Organización Panamericana de la Salud (OPS)/Organización Mundial MOLLOY, A. de la Salud (OMS), Uruguay, 30 pp.

2014 Could 'selfies' be contributing to head lice among teenagers? Independent consultado 22/12/2016. http://www.independent.co.uk/news/world/americas/could-selfies-be-contributing-to-head-lice-among-teens-9151317.html

OAKLANDER, $\mathrm{M}$.

2015 Head Lice in 25 States Are Now Resistant to Treatment. Health public health consultado 22/12/2016. http://time.com/4000857/lice-treatment/

OLIVEIRA-FILHO, A.M.

1997 Uso de Nuevas Herramientas para el Control de Triatominos en diferentes situaciones Entomológicas en el Continente Americano. Revista da Sociedade Brasileira de Medicina Tropical 30(1):41-46.

RAGHAVAN, M., SKOGLUND, P., GRAF, K.E., METSPALU, M., ALBRECHTSEN, A., RASMUSSEN, S., STAFFORD, T.W. JR, ORLANDO, L., METSPALU, E., KARMIN, M., ROOTSI, S., MAGI, R., CAMPOS, P.F., BALANOVSKA, E., BALANOVSKY, O., MOLTKE, I., TAMBETS, K., KHUSNUTDINOVA, E., LITVINOV, S., OSIPOVA, L.P., FEDOROVA, S.A., VOEVODA, M.I., SICHERITZ-PONTEN, T., BRUNAK, S., DEMESHCHENKO, S., KIVISILD, T., DEGIORGIO, M., NIELSEN, R., JAKOBSSON, M. \& WILLERSLEV, E.

2014 Upper Palaeolithic Siberian genome reveals dual ancestry of Native Americans. Nature 505:87-91. doi:10.1038/nature12736

REED, D.L., LIGHT, J.E., ALLEN, J.M. \& KIRCHMAN, J.

2007 Pair of lice lost or parasites regained: the evolutionary history of anthropoid primate lice. BMC Biology 5:1-11 doi:10.1186/1741-7007-5-7.

RETANA-SALAZAR, A.P.

1996 Evidencia Parasitológica sobre la filogenia de los homínidos y los cébidos. Revista de Biología Tropical 44(2):391-394. 
RETANA-SALAZAR, A.P.

2005 Tras las huellas del Hombre Americano: Un enfoque parasitológico. Revista de Antropología Experimental 5: 1-10.

RETANA-SALAZAR, A.P.

2006 Filogenia y Revisión Taxonómica de la Superfamilia Pediculoidea n. stat. (Anoplura: Insecta). BRENESIA 66:15-24.

RETANA-SALAZAR, A.P. \& RAMÍREZ-MORALES, R.

2006 Establecimiento de un nuevo género de piojos (Phthiraptera: Pediculidae) asociado al hombre (Primates: Hominidae). BRENESIA 65: 61-70.

RETANA-SALAZAR, A.P. \& RETANA-SALAZAR, S.A.

2015 Cambio Climático. Su efecto sobre las plagas y las consecuencias en los sistemas de producción alimentaria. Editorial Ciencia, Arte y Tecnología. San José, Costa Rica 87pp.

RETANA-SALAZAR, A.P \& RODRÍGUEZ-ARRIETA, J.A.

2016 Estudio fotomicrográfico de la genitalia y estructuras accesorias de las formas del género Pediculus Linneo 1758 asociadas al hombre y los monos del Nuevo Mundo (Anoplura: Phthiraptera). Revista gaditana de Entomología 7(1):489-510.

STENSETH, N.C. \& DUNLOP, E.S.

2009 Evolution: Unnatural selection. Nature 457:803-804, doi:10.1038/457803 ${ }^{\mathrm{a}}$

TAKKEN, W. \& WEISS, M.

1999 La técnica de los insectos estériles en la lucha contra la mosca tsé-tsé en África. OIEA Boletin 20(3):20-24.

TAYLOR, E.B., BOUGHMAN, J.W., GROENENBOOM, M., SNIATYNSKI, M., SCHLUTER, D. \& GOW, J.L.

2006 Speciation in reverse: morphological and genetic evidence of the collapse of a threespined stickleback (Gasterosteus aculeatus) species pair. Molecular Ecology 15: 343-355.

VERACX, A., RIVET, R., MCCOY, K.D., BROUQUI, P., RAOULT, D.

2012 Evidence That Head and Body Lice on Homeless Persons Have the Same Genotype. PLoS ONE 7(9): e45903. doi:10.1371/journal.pone.0045903

WALLACE, A.R.

1855 On the Law Which Has Regulated the Introduction of New Species. Annals and Magazine of Natural History (2do Series) 16:184-196.

WALTHER, G-R, BEIßNER, S. \& BURGA, C.A.

2005 Trends in the upward shift of alpine plants. Journal of Vegetation. Science 16(5):541-548 doi: 10.1658/1100-9233(2005)16[541:TITUSO]2.0.CO;2

WIKELSKI M \& THOM C.

2000 Marine iguanas shrink to survive El Nino -Changes in bone metabolism enable these adult lizards to reversibly alter their length. Nature 403:37-38.

WILEY, E.O.

1981 Phylogenetics, The Theory and Practice of Phylogenetic Systematics. Wiley-Interscience, New York. 1981. 439 pp.

WILKE, T., VÄINOLÄ, R. \& RIEDEL, F.

2009 Patterns and Processes of Speciation in Ancient Lakes. In: Proceedings of the Fourth Symposium on Speciation in Ancient Lakes, Berlin, Germany. Springer Science \& Business Media, $236 \mathrm{pp}$.

YOON, K.S., PREVITE, D.J., HODGDON, H.E., POOLE, B.C., KWON, D.H., ABO EL-GHAR, G.E., LEE, S.H. \& CLARK, J.M.

2014 Knockdown Resistance Allele Frequencies in North American Head Louse (Anoplura: Pediculidae) Populations. Journal of Medical Entomology 51(2):450-457. doi: http://dx.doi. org/10.1603/ME13139

ZHAO, Y, GUO, N., XUN, M., XU, J., WANG, M. \& WANG, D.

2011 Sociodemographic characteristics and risk factor analysis of Demodex infestation (Acari: Demodicidae). Journal of Zhejiang University-SCIENCE B (Biomedicine \& Biotechnology) 12(12):998-1007. 